\title{
Exhaled breath condensates and COPD
}

\section{To the Editors:}

BORRILL et al. [1] have recently provided a timely review of exhaled breath condensates (EBC) in chronic obstructive pulmonary disease. However, there are several issues that deserve comment. BORRILL et al. [1] argue that although it would be useful to use dilutional indicators for estimating the dilution of respiratory droplets from the airway lining fluid (ALF) by water vapour, none of these have been "validated." Dilution is both extreme $(\sim 1: 20,000)$ and variable and represents a significant challenge for the application of the EBC procedure. Contrary to their assertion, there is no need to show that dilutional indicators "diffuse through cell membranes at a constant rate" [1]. It is only necessary to show that concentrations of dilutional indicators in the ALF remain equal to those in the plasma and that they are neither produced nor destroyed in the lungs. There is good reason to believe that urea meets these criteria as it readily diffuses passively between the blood and airspaces [2], and it is neither produced in nor lost from the lungs. Similarly, the selection of total nonvolatile cation concentrations or conductivity of lyophilised samples is based on the assumptions that, because of rapid movement of water across the pulmonary capillaries and epithelium, the osmolality of the plasma and ALF are normally similar under resting conditions [3-5]. Reasonable agreement between the dilution estimated from these three indicators has been published, providing strong evidence that they can be used to estimate dilution of ALF in EBC [6]. It should be emphasised that without a measure of dilution, neither the concentrations nor changes concentrations of EBC constituents can provide reliable information about ALF. Furthermore, salivary contamination of the EBC should routinely be evaluated: sensitive and inexpensive amylase procedures that can detect 1:200,000 dilution of salivary amylase are available.

Dilutional indicators are useful for calculating ALF concentrations of nonvolatile constituents in EBC but cannot be used for volatile substances (e.g. $\mathrm{H}_{2} \mathrm{O}_{2}$ and $\mathrm{NH}_{3}$ ). In general, the $\mathrm{EBC}$ approach should not be used to evaluate either ALF concentrations or excretion rates of volatile substances because recovery of these markers can be unpredictably altered by numerous factors in the lungs and collecting device, including air-to-water distribution coefficients at different temperatures, $\mathrm{pH}$, air flow, etc.

There are persuasive grounds for doubting that EBC $\mathrm{pH}$ can ever yield reliable values for ALF $\mathrm{pH}$. It has been shown definitively that $\mathrm{NH}_{4}{ }^{+}$represents $\sim 90 \%$ of all cations in most samples of EBC, as judged from conductivity and ion chromatography [7]. Since there is much less $\mathrm{NH}_{4}{ }^{+}$in $\mathrm{EBC}$ when collected from endotracheal or tracheostomy tubes, most of the $\mathrm{NH}_{4}{ }^{+}$must be derived from extrapulmonary structures, particularly the mouth, much of it from bacterial degradation of urea to $\mathrm{NH}_{3}$ [8]. The assertion that EBC $\mathrm{pH}$ is not influenced by oral $\mathrm{NH}_{3}$ violates basic chemical principles, since $\mathrm{NH}_{3}$ has a $\mathrm{pK}_{\mathrm{b}}$ of $\sim 5$ and $\mathrm{NH}_{4}{ }^{+}$derived from the mouth with similar concentrations of respiratory $\mathrm{HCO}_{3}{ }^{-}$represent the most abundant acids and bases in most EBC samples. Generally, lower concentrations of acetate and other volatile anions are sometimes observed in EBC, but these may also be derived from oral bacteria.

Much of the confusion regarding EBC $\mathrm{pH}$ is related to attempts to remove $\mathrm{CO}_{2}$ by briefly purging samples with inert gases. Even if successful, this would yield $\mathrm{pH}$ values that differ from those in the lungs, where $\mathrm{CO}_{2}$ is always present. Furthermore, purging with inert gases is not selective since it only removes a fraction of the $\mathrm{CO}_{2}$ and can also remove some $\mathrm{NH}_{3}$, volatile anions and water, thereby altering $\mathrm{pH}$. Subtle differences in purging procedures can have important effects on the EBC $\mathrm{pH}$ and probably contribute to major differences reported for EBC $\mathrm{pH}$ by different laboratories. Nor has sufficient thought been given to the buffering capacity of the EBC. The overwhelming concentrations of $\mathrm{NH}_{4}{ }^{+}$and $\mathrm{HCO}_{3}{ }^{-}$in $\mathrm{EBC}$, which are added outside the lungs, tend to obscure any $\mathrm{pH}$ signal derived from the lungs.

The principal advantage of exhaled breath condensate approach is that samples can be collected from the mouth rather than the airways of the lungs. Unfortunately this also represents one of its chief weaknesses, because of the abundance of volatile substances that are generated in the saliva and mouth which contaminate the exhaled air.

\section{R.M. Effros}

LABioMed, Harbour UCLA Medical Center, Torrance, CA, USA.

\section{STATEMENT OF INTEREST}

None declared.

\section{REFERENCES}

1 Borrill ZL, Roy K, Singh D. Exhaled breath condensate biomarkers in COPD. Eur Respir J 2008; 32: 472-486.

2 Effros RM, Murphy C, Ozker K, Hacker A. Kinetics of urea exchange in air-filled and fluid-filled rat lungs. Am J Physiol 1992; 263: L619-L626.

3 Tarran R. Regulation of airway surface liquid volume and mucus transport by active ion transport. Proc Am Thorac Soc 2004; 1: 42-46.

4 Boucher RC. Molecular insights into the physiology of the "thin film" of airway surface liquid. J Physiol 1999; 516: 631-638.

5 Jayaraman S, Song Y, Verkman AS. Airway surface liquid osmolality measured using fluorophore-encapsulated liposomes. J Gen Physiol 2001; 117: 423-430.

6 Effros RM, Biller J, Foss B, et al. A simple method for estimating respiratory solute dilution in exhaled breath condensates. Am J Respir Crit Care Med 2003; 168: 1500-1505.

7 Effros RM, Casaburi R, Su J, et al. The effects of volatile salivary acids and bases upon exhaled breath condensate pH. Am J Respir Crit Care Med 2006; 168: 1500-1505.

8 Effros RM, Wahlen K, Bosbous M, et al. Dilution of respiratory solutes in exhaled condensates. Am J Respir Crit Care Med 2002; 165: 663-669. 